\title{
Synthesis, Characterization and Thermal Properties of Poly(MMA)/Organoclay Nanocomposites
}

\author{
NEVİN ÇANKAYA \\ Department of Chemistry, Uşak University, Uşak, Turkey
}

\begin{abstract}
In this study, the synthesis, characterization, and thermal properties of poly(methyl methacrylate) (MMA) polymer/clay based nanocomposites were investigated by in situ polymerization. At the characterizations of nanomaterials FTIR, XRD, and thermal techniques were used. It was determined from XRD and TGA measurements that the morphology of nanocomposites was exfoliated when the clay content in the polymer matrix was kept at $3 \%$ and $5 \%$. From thermal analysis, a positive correlation was observed between the clay ratio and thermal stability of nanomaterials.
\end{abstract}

Keywords: Polymer/clay nanocomposite, organoclay, thermal stability, in-situ polymerization, methyl methacrylate.

DOI: $10.7176 / \mathrm{CMR} / 12-3-02$

Publication date:March $31^{\text {st }} 2020$

\section{Introduction}

The need for the development of new materials with better properties is increasing day by day. Nanocomposites are obtained by mixing two different materials in certain proportions. The thermal and mechanical properties of composites are superior to pure polymer. The use of polymers in composites provides many advantages in terms of flexibility, lightness and easy workability. Polymer nanocomposites exhibit many different properties such as important mechanical resistance, water and oxygen barrier, dimensional stability, thermal stability, flame retardant, chemical resistance, optical, magnetic and electrical properties [1].

Recent advances in material technologies have encouraged the development of various preparation strategies and applications of new polymer/clay nanocomposites. Thanks to new syntheses, new polymer/clay composites have been created that can be used in a variety of fields such as aviation, automobile, construction, oil, biomedical and wastewater treatment. These composites are considered as promising advanced materials due to their superior density, strength, large surface areas, high elastic modulus, flame retardant, thermomechanical, optoelectronic, magnetic properties [2]. Even with the addition of a small amount of clay, many properties of the polymer can be modified, such as adsorption, ion exchange capacity, thermal and solvent resistance [3-4]. That's why, companies invest billions of dollars annually to develop new polymer/clay composite materials. Numerous polymers/clay nanocomposites have been synthesized over the past 20 years, for example, nylon 6 [5-7], nylon 10,10 [8], polystyrene [9-14], polypyrol [15], polyimide [16-17], polyacrylate [18], polyacrylonitrile [19].

Our aim in this study is to distribute natural, abundant, cheap and thermal-resistant clay type (NaMontmorillonite) and poly(methyl methmetacrylate) (MMA) within each other, and to obtain new polymer/clay materials with good thermal and mechanical resistance. Unlike the literature, nanocomposites of the C10A organoclay were synthesized with the MMA monomer. When the organoclay type was changed, results similar to the literature were found. The thermal stability of the composites also increased with the increase in the amount of clay.

\section{Experimental}

\subsection{Materials}

Nanoclay 1-135 (C10A) was provided from Esan-Eczacıbaş1. The organic modifier of Nanoclay 1-135 is dimethyl, benzyl, hydrogenated tallow, quaternary ammonium cation with the particle size range of $<15 \mu$, where tallow is $\sim 65 \% \mathrm{C} 18, \sim 30 \% \mathrm{C} 16, \sim 5 \% \mathrm{C} 14$ [20]. For nanocomposite synthesis, methyl methacrylate (MMA) as monomer, and benzoyl peroxide (BPO) (Aldrich) were used as initiator and 1,4-Dioxane and ethyl alcohol as solvent.

\subsection{Instrumental Measurements of Nanocomposite}

The FTIR spectra of all samples were performed with a PerkinElmer Spectrum Two (UATR) IR spectrometer in the range of 4000-450 $\mathrm{cm}^{-1}$. XRD patterns were obtained using a Bruker Axs D8 Advance diffractometer with a back monochromator and a $\mathrm{Cu}$ target and $\mathrm{K} \alpha(\lambda=1.5418 \mathrm{~nm})$ in $2 \theta=10-45^{\circ}$ (step of $0.01^{\circ}$, at room temperature). Thermal analyzes were obtained with a Hitachi 7000 TGA/DTA/DTG simultaneous system a heating rate of $10^{\circ} \mathrm{C}$ $\mathrm{min}^{-1}$ in nitrogen atmosphere.

\subsection{Preparation of Poly(MMA)/Organoclay Nanocomposites}

Poly(MMA)/organoclay nanocomposites were prepared with in-situ method. 3\% and 5\% amount of C10A 
organonanoclay was dispersed in 1,4-dioxane and stirred by magnetic stirrer at $70{ }^{\circ} \mathrm{C}$ for $24 \mathrm{~h} .1 \mathrm{M}$ MMA monomer was dissolved in 1,4-dioxane at room temperature in another flask. Benzoyl peroxide was added as a free radical initiator to the $3 \%$ and $5 \%$ organoclay added monomer mixture in separate bottles. In separate magnetic stirrer, polymer/organoclay composites were formed by mixing at $73{ }^{\circ} \mathrm{C}$ for 48 hours. The composites were precipitated in excess ethyl alcohol, removed from impurities, dried in the oven, and sifted through a 20micron sieve [21-22].

\section{Results and Discussions}

\subsection{FTIR Spectroscopy}

Figure 2 shows FTIR spectra of poly(MMA)/3\%C10A and poly(MMA)/5\%C10A nanocomposites. The characteristic feature of the clay is that it contains molecules such as $\mathrm{SiO}_{2}, \mathrm{Al}_{2} \mathrm{O}_{3}, \mathrm{MgO}$. When the FTIR spectra of Na-Montmorillonite clay are examined, it was observed that the O-H stretch vibration peaked at 3624 and O-H bending vibration at $1450 \mathrm{~cm}^{-1}$, Si-O stretch at 1010 and bending vibration at $514 \mathrm{~cm}^{-1}$, Al-OH vibration at 913 $\mathrm{cm}^{-1}$ and $\mathrm{Mg}-\mathrm{O}$ vibration at $475 \mathrm{~cm}^{-1}$. The clay peaks are observed in the C10A organoclay as mentioned above. Also, includes dimethyl benzyl alkyl chain quaternary ammonium chloride structures used in the modification. The following are the peaks from the chemical modifier; aliphatic $\mathrm{N}-\mathrm{CH}_{3}$ vibration at $2840 \mathrm{~cm}^{-1}$, aliphatic $\mathrm{CH}_{2}$ vibration at $1465 \mathrm{~cm}^{-1}$, symmetric and asymmetric $\mathrm{C}-\mathrm{H}$ stretching vibration at $2920 \mathrm{~cm}^{-1}$ and aromatic $\mathrm{C}=\mathrm{C}$ stretching vibration at $1644 \mathrm{~cm}^{-1}$ [20]. The most characteristic bands observed for poly(MMA) units in nanocomposites are seen in $\left(\mathrm{cm}^{-1}\right)$ 2850-3000 (aliphatic $\left.\mathrm{C}-\mathrm{H}\right), 1725(\mathrm{C}=\mathrm{O}$ ester stretch), 1144 (C-O stretch-which is this frequency is quite variable) [22-23]. In nanocomposites, all these peaks from the homopolymer are observed. On the other hand, some peaks characteristic of clay are also seen in composites. From these results, it can be said that the organomodified clay presents in polymer matrix as is reported by other articles [21-25].

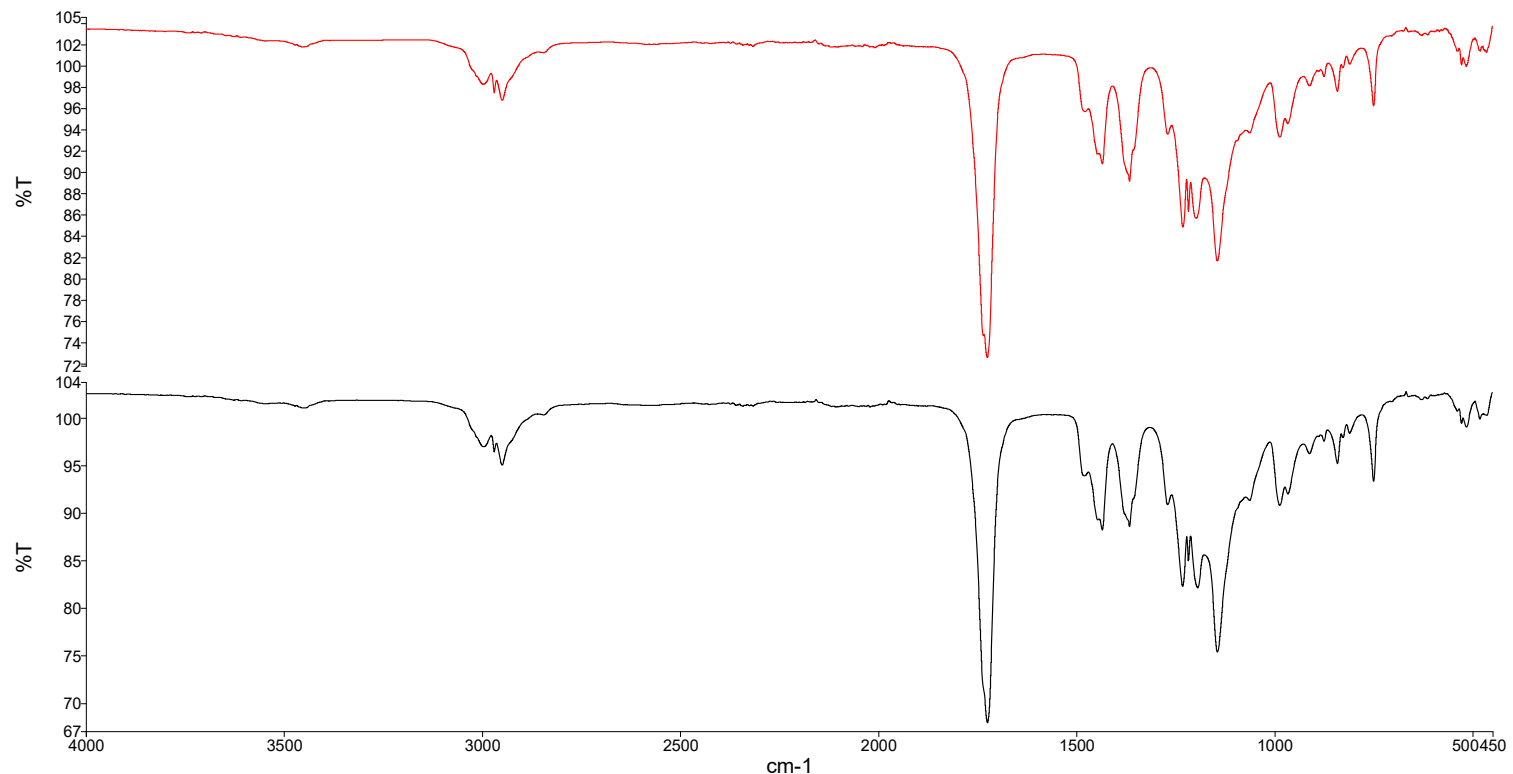

Figure 2. FTIR spectra of poly(MMA)/3\%C10A, poly(MMA)/5\%C10A nanocomposites, in order from top to down

\subsection{XRD Measurements}

$\mathrm{X}$-ray diffraction is the preliminary technique to verify whether the layered structure has altered or not. In the literature, the characteristic crystalline peaks of the diffraction angle of $\mathrm{C} 10 \mathrm{~A}$ organoclay was $2 \theta=5.4^{\circ}, 20^{\circ}, 22^{\circ}$ $(\mathrm{d}=1.64,0.44,0.40 \mathrm{~nm})$ [20]. The distribution of the polymer between the layers of the clay causes that a clear XRD peak in the nanocomposites to be unreadable. The absence of component-specific peaks in nanocomposite materials can be explained by the fact that the polymer is intercalated between clay layers and clay layers become so irregular that they cannot give an XRD signal [20-27], therefore it can be considered as an exfoliated structure. Also, all peaks present in the XRD curve of the clays are not observed in the nanocomposites. The XRD patterns of the poly(MMA)/organoclay nanocomposites are shown in Fig.3. 


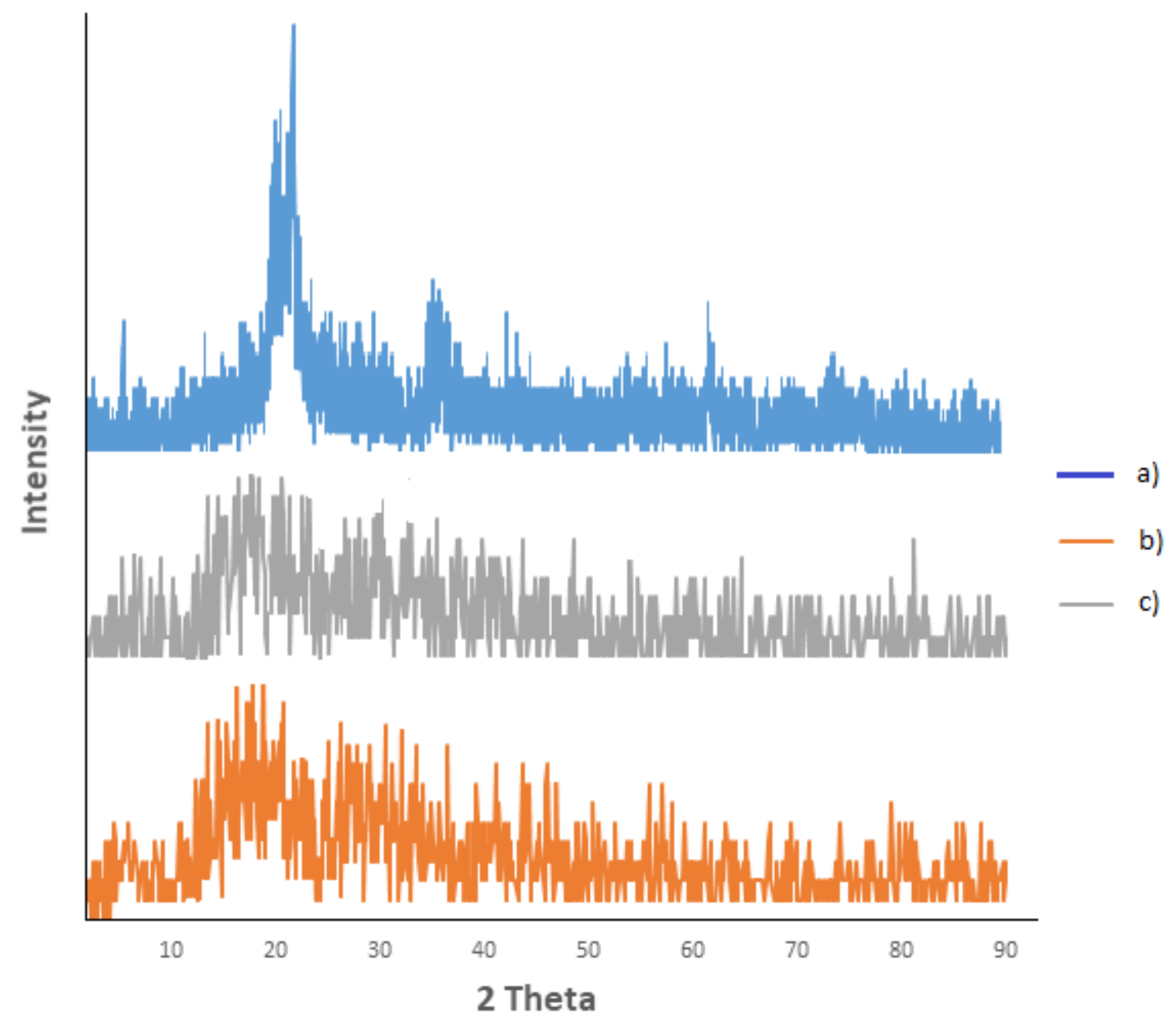

Figure 3. XRD patterns of a) $\mathrm{C} 10 \mathrm{~A}$ organoclay b) poly(MMA) $/ 3 \% \mathrm{C} 10 \mathrm{~A}$ c) poly(MMA) $/ 5 \% \mathrm{C} 10 \mathrm{~A}$

\subsection{Thermal Characterization}

Thermogravimetric analysis method helps determining the thermal stabilities of polymer/clay nanocomposites and provides information about their thermal behavior. The decomposition temperature and the temperature at weight loss are taken as a measure of thermal stability. When nanocomposites' thermal behaviors are compared, it is observed that composites containing more clay have better thermal stability. These thermal changes prove that polymer chains break into the clay galleries and form nanocomposites. The nanodispersion of polymer molecules in silicate layers limits thermal movement, which increases thermal stability. It was observed that thermal stability of nanocomposites formed with clay increased with the increasing amount of clay in the composite, resulting in a clay thermal barrier [20-22, 24-27]. The thermal properties of nanocomposites were determined by TGA/DTA/DTG simultaneous system. The degradation of the composites from the thermogram was observed at three levels. Important thermal results for nanocomposites are given in Table 1, the thermal curves of nanocomposites are shown in Figure 4, and comparatively thermal curves are given in Figure 5. 


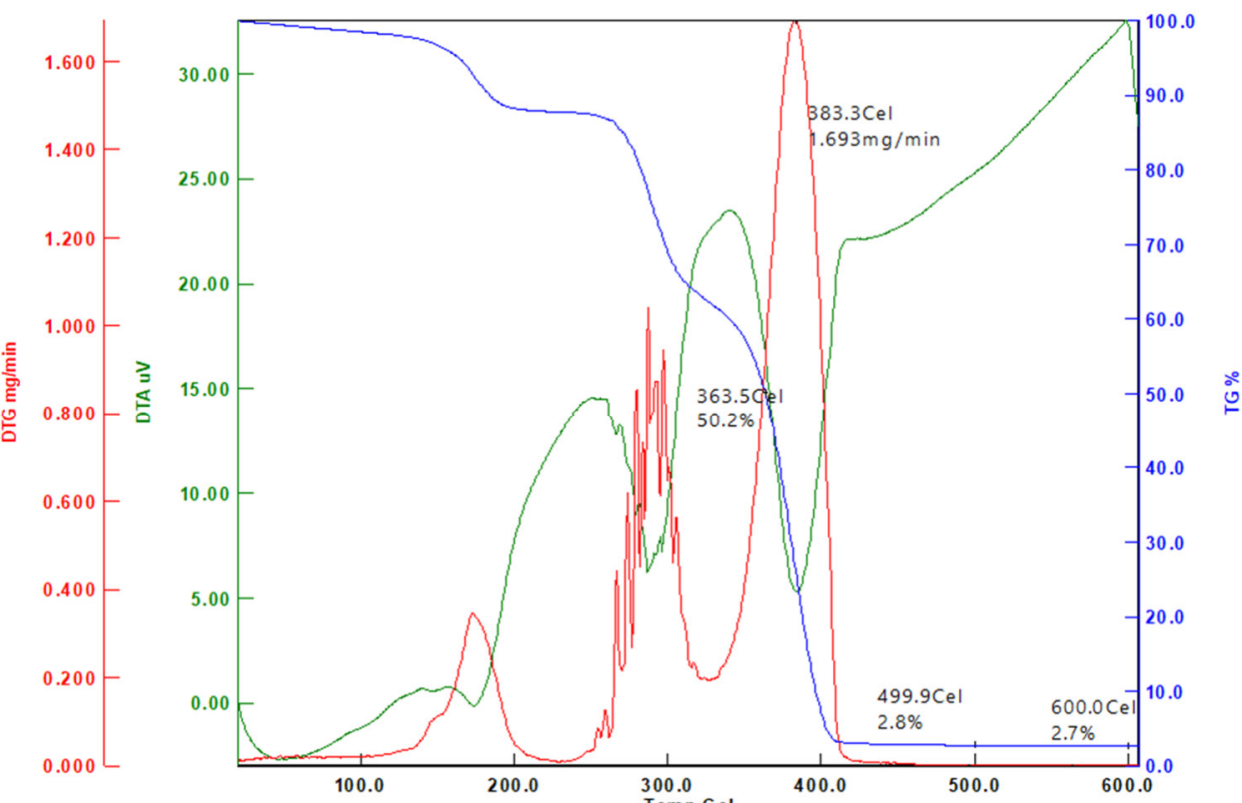

a)

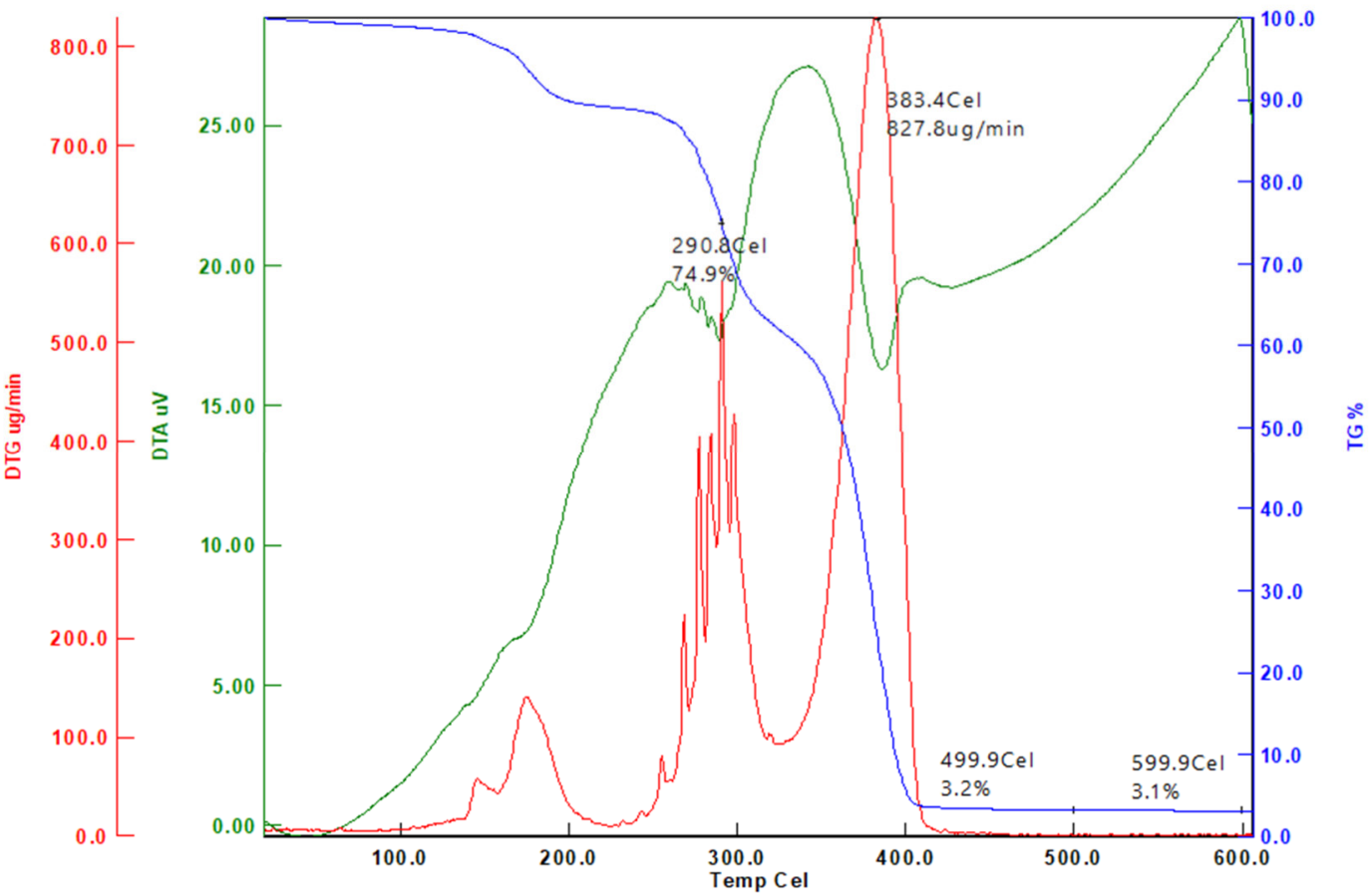

b)

Figure 8. The TGA/DTA/DTG curves of the a) poly(MMA)/3\%C10A b) poly(MMA)/5\%C10A, respectively 


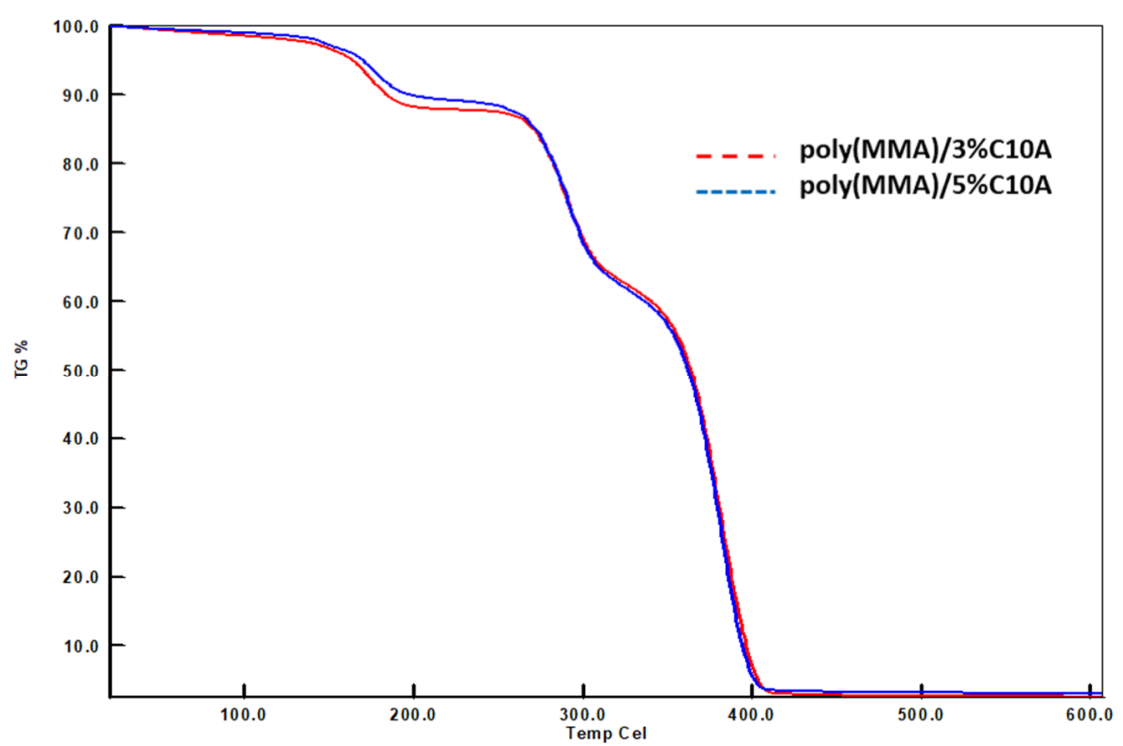

Figure 5. Comparative TGA curves for nanocomposites

Table 1. Some thermal data of nanocomposites

\begin{tabular}{|c|c|c|c|c|c|c|c|}
\hline Sample & $\begin{array}{l}\text { Max. Decomp. } \\
\text { Temp. }\left({ }^{\circ} \mathrm{C}\right)\end{array}$ & $\begin{array}{l}\text { Temp. of } \\
25 \% \\
\text { weight } \\
\text { loss at } \\
\left({ }^{\circ} \mathrm{C}\right) \\
\end{array}$ & $\begin{array}{l}\text { Temp. of } \\
50 \% \\
\text { weight } \\
\text { loss at } \\
\left({ }^{\circ} \mathrm{C}\right)\end{array}$ & $\begin{array}{l}\text { \%Weight } \\
\text { loss at } \\
(450 \text { and } \\
\left.500^{\circ} \mathrm{C}\right)\end{array}$ & $\begin{array}{c}\% \\
\text { Residue } \\
\text { at } \\
\left(5_{00}^{\circ} \mathbf{C}\right)\end{array}$ & $\begin{array}{c}\% \\
\text { Residue } \\
\text { at } \\
\left(550^{\circ} \mathrm{C}\right)\end{array}$ & $\begin{array}{c}\% \\
\text { Residue } \\
\text { at } \\
\left(600^{\circ} \mathrm{C}\right)\end{array}$ \\
\hline $\begin{array}{l}\text { poly(MMA) } \\
/ 3 \% \text { C10A }\end{array}$ & $173,288,383$ & 291 & 363 & 97 & 2.8 & 2.7 & 2.7 \\
\hline $\begin{array}{l}\text { poly(MMA) } \\
/ 5 \% \mathrm{C} 10 \mathrm{~A}\end{array}$ & $174,291,383$ & 291 & 363 & 97 & 3.2 & 3.2 & 3.1 \\
\hline
\end{tabular}

\section{Conclusion}

In this research, polymer/clay based nanocomposites synthesis, characterization, and thermal properties of poly(methyl methacrylate) (MMA) were investigated by in situ polymerization. FTIR, XRD, and TGA techniques were used at characterizations of nanomaterials. From XRD and thermal measurements, it was observed that the morphology of nanocomposites was exfoliated when the clay content in the polymer matrix was kept at 3\% and $5 \%$. It was observed that the thermal stability of nanomaterials increased as the clay rate increased from thermal analysis. Given that polymer/clay composites are used in various fields such as innovative synthesis methods, aviation, automobile, construction, packaging, petroleum, biomedical and wastewater treatment, we hope that this study will lead the literature and companies.

\section{Acknowledgement}

The authors would like to thank to Uşak University Research Fund for financial support of this work (2016/TP001).

\section{REFERENCES}

[1] Gacitua, W.; Ballerini, A.; Zhang, J. Maderas: Cienc Technol, (2005), 7(3), 159-178.

[2] C. Soykan, M. Akbay, Journal of Material Science and Technology Research, 2019, 6, 22-33.

[3] Li, Y.; Zhao, B.; Xie, S.; Zhang, S.Polym Int (2003),52,892.

[4] Salahuddin, N.; Akelah, A.Polym Adv Technol (2002),13,339.

[5] Zhang, G.; Yan, D. J Appl Polym Sci (2003),88,2181.

[6] Ma, C. M.; Kuo, C.; Kuan, H.; Chiang,C. J Appl Polym Sci (2003),88,1686.

[7] Kyu, T.; Zhou, Z.L.; Zhu, G.C.; Tajuddin, Y.; Qutubudddin, S. J Polym Sci Part B: Polym Phys (1996),34,1761.

[8] Hasegawa, N.; Okamoto, H.; Kawasumi, M.; Usuki, A. J Appl Polym Sci (1999),74,3359.

[9] Moet, A.; Akelah, A. Mater Lett (1993),18,97.

[10] Moet, A.; Akelah, A. J Mater Sci (1996),28,3589.

[11] Chen, G.; Liu, S.; Chen, S.; Qi, Z. Macromol Chem Phys (2001),202,1189.

[12] Tseng, C.; Wu, J.; Lee, H.; Chang,F. J Appl Polym Sci (2002),85,1370. 
[13] Yeh, J.; Chin, C.; Chang, S. J Appl Polym Sci (2003),88,3264.

[14] A. Kurt, R. Yavuz, G. Bozdağ, Synthesis of Polystyrene-Clay Nanocomposites, Investigation of Thermal and Optical Properties, Adiyaman University Journal of Science, 3 (2) (2013) 58-70.

[15] Yano, K.; Usuki, A.; Okada,A.; Kurauchi, T.; Kamigaito, O. J Polym Sci Part A: Polym Chem (1993),31,2493.

[16] Yano, K.; Usuki, A.;Okada, A. J Polym Sci Part A: Polym Chem (1997),35,2289.

[17] Chen, Z.; Huang, C.; Liu, S.; Zhang, Y.; Gong, K. J Appl Polym Sci (2000), 75,796.

[18] Seçkin, T.; Gültek, A.; İçduygu, M.G.; Önal, Y. J Appl Polym Sci (2002),84,164.

[19] Önal, M.; Sarıkaya, Y.; Alemdaroğlu, T.; Bozdoğan, İ. Turk J Chem (2003),27,683

[20] N. Çankaya, R. Şahin, Chitosan/Clay Bionanocomposites: Structural, Antibacterial, Thermal and Swelling Properties, Cellulose Chemistry and Technology, 53(5-6), 537-549, 2019.

[21] N. Çankaya, Poly(MPAEMA)/Clay Nanocomposites: Synthesis, Characterization, Structural, and Thermal Properties, 2020, Unpublished Data.

[22] A. Kurt, Z. Çağlayan, H. S Bektaş, Preparation of Poly(Methyl Methacrylate)/Clay Nanocomposites and Investigation of some Physical Properties, Sigma Journal of Engineering and Natural Sciences, 32, 71-84, 2014.

[23] H. M. Harisa, S. Kathiresan, S. Mohan, FT-IR and FT-Raman Spectra and Normal Coordinate Analysis of Poly methyl methacrylate, Der Pharma Chemica, 2010, 2(4): 316-323

[24] A. Kurt, O. K. Topsoy, Preparation of Novel Coumarin Cyclic Polymer/Montmorillonite Based Nanocomposites, Russian Journal of Applied Chemistry, 2017, 90(12), 2019-2027.

[25] A. Delibas M. Alparslan, Turk. J. Chem., 39, 630 (2015), https://doi.org/10.3906/kim-1410-35

[26] A. Tcherbi-Narteh, M. Hosur, S. Jeelani, Effects of Different Montmorillonite Nanoclay Loading on Cure Behavior and Properties of Diglycidyl Ether of Bisphenol A Epoxy, Hindawi Publishing Corporation Journal of Nanomaterials, 2016, 1-12, http://dx.doi.org/10.1155/2016/3840348

[27] A. Tcherbi-Narteh, M. Hosur, E. Triggs, P. Owuor, S. Jelaani, Viscoelastic and thermal properties of full and partially cured DGEBA epoxy resin composites modified with montmorillonite nanoclay exposed to UV radiation, Polymer Degradation and Stability, 101, 81-91, 2014. 